УДК 378.14

DOI 10.23951/2307-6127-2020-1-146-153

\title{
ОПРЕДЕЛЕНИЕ ОБЛАСТИ ЦЕНТРАЛИЗОВАННОГО ПРИМЕНЕНИЯ ИНФОРМАЦИОННО-КОММУНИКАЦИОННЫХ ТЕХНОЛОГИЙ В ПРОЦЕССЕ ПОДГОТОВКИ КАДРОВ ВЫСШЕЙ КВАЛИФИКАЦИИ
}

\author{
В. С. Малышев
}

\section{Православный Свято-Тихоновский гуманитарный университет, Москва}

Условия реформирования системы подготовки кадров высшей квалификации характеризуются растущей потребностью обработки больших массивов информации в профессиональной деятельности. На этом фоне выпускник программы подготовки кадров высшей квалификации должен быть готов к самостоятельному выявлению проблемных зон с целью индивидуального или коллективного исследования и получения нового знания, направленного на решение поставленных задач. Отсюда следует, что содержание программы подготовки должно включать формы и виды будущей профессиональной деятельности выпускника. Исследование направлено на выявление средств информационно-коммуникационных технологий, которые могут быть централизованно применены для обеспечения образовательного процесса с целью создания базовых условий, которые позволят обозначить верное направление развития индивидуальной образовательной траектории обучающегося в ходе освоения программы подготовки кадров высшей квалификации. Представлено описание выявления области конкретизации централизованного применения средств информационно-коммуникационных технологий при проектировании информационной образовательной среды в подготовке кадров высшей квалификации на основе теоретико-эмпирического анализа образовательного процесса подготовки научно-педагогических кадров в аспирантуре.

Ключевые слова: информационная образовательная среда, подготовка кадров выстей квалификачии, параметры проектирования, образовательный прочесс в аспирантуре.

С момента вступления в силу Федерального закона № 273 «Об образовании в РФ» подготовка кадров высшей квалификации в России отнесена к третьему уровню высшего образования. С 2014 г. программы подготовки кадров высшей квалификации регламентированы федеральными государственными образовательными стандартами (ФГОС ВО). Высшая квалификация предполагает оперативную деятельность с большими объемами информации, умение обращения с ней, компетенции сообразного применения этих умений в достижении целей работы. Индивидуализация образовательных результатов, обусловленная личностными характеристиками обучающегося и областью его научного исследования, также является специфической характеристикой программ подготовки кадров высшей квалификации. Текущее реформирование системы высшего образования отражает поиск ее оптимальных форм, отвечающих современным требованиям, и в первую очередь - взаимосвязи образовательного процесса с информационными процессами. В этом отношении информационная образовательная среда в подготовке кадров высшей квалификации оказывается одновременно объектом приложения организационно-педагогических усилий вузов и предметом педагогического исследования условий ее эффективности. Необходимость определения блока задач по подготовке кадров высшей квалификации в информационной образовательной среде, относящихся к организационно-педагогическому аспекту, послу- 
жила предпосылкой проблемы данного исследования. Содержание понятия «информационная образовательная среда вуза» [1] рассматривается как информационная система [2], образованная на базе и с помощью информационно-коммуникационных технологий, являющаяся средством управления образовательной деятельностью и одновременно ведущим образовательным средством обучающегося [3]. Таким образом, предпринятое исследование нацелено на выявление требований к информационной образовательной среде как информационной системе, направленной на решение организационно-педагогических задач в процессе подготовки кадров высшей квалификации. Его последовательный анализ по таким направлениям, как требования к результатам, принципы формирования содержания образования и осуществление в вузе, сфокусирован на выявлении параметров проектирования информационной образовательной среды в подготовке кадров высшей квалификации.

Теоретической базой исследования являются результаты исследований отечественных и зарубежных специалистов в области высшего образования, в том числе и области, соответствующей, в сегодняшней терминологии, уровню подготовки кадров высшей квалификации. При рассмотрении требований к результатам и специфики подготовки кадров высшей квалификации мы обращались к работам таких авторов, как В. В. Лаптев, С. А. Писарева, Б. И. Бедный, А. А. Миронос, Г. У. Матушанский, Л. Н. Макарова, Л. А. Шаршов, Л. В. Непомнящая и др. Анализируя методологию организации научных исследований и методические материалы по реализации программ подготовки кадров высшей квалификации, мы опирались на работы В. В. Серикова, А. Р. Сулеймановой, Н. И. Лыгиной, Г. Б. Скока, Э. П. Бакшеевой, Т. Б. Захарова, Г. А. Игнатьева. Вопросы информатизации образования; назначение, применение, структура информационной образовательной среды рассмотрены в исследованиях И. В. Роберт, С. Л. Атанасяна, И. Г. Захаровой, И. Н. Розиной, В. В. Гриншкуна, О. И. Соколовой, Т. A. Mikropoulos, A. Natsis и др. Таким образом, степень разработанности данной проблемы, создает основу исследования по выявлению области применения информационно-коммуникационных технологий при проектировании информационной образовательной среды в подготовке кадров высшей квалификации.

В рамках решения задач по достижению поставленной цели исследования мы провели теоретико-эмпирический анализ процесса подготовки кадров высшей квалификации. В первую очередь нас интересовали общие проблемы, возникающие в ходе осмысления и выбора направлений и средств достижения образовательных результатов. Во-вторых, принципы формирования содержания программы подготовки. Третьим критерием анализа стало выявление видов и форм деятельности по реализации образовательной программы подготовки кадров высшей квалификации с централизованным применением информационнокоммуникационных технологий. Полученные в ходе теоретического анализа научно-педагогической литературы данные были конкретизированы в результате изучения образовательного процесса подготовки научно-педагогических кадров в аспирантуре Православного Свято-Тихоновского гуманитарного университета (ПСТГУ). Мы изучили локальные нормативные акты, регламентирующие данный процесс, а также провели интернет-опрос представителей профессорско-преподавательского состава и аспирантов, участвующих в реализации соответствующих образовательных программ. Интернет-опрос был направлен на выявление потребностей участников в усовершенствовании учебного и научно-исследовательского процессов, в том числе и с применением средств ИКТ. Были проанализированы ответы 15 сотрудников из числа ППС, занимающихся организационной, преподавательской, научно-исследовательской деятельностью в рамках реализации образовательных программ подготовки научно-педагогических кадров, и 30 аспирантов разных годов обучения 
и направлений подготовки. На основе данных, полученных из научно-педагогических источников, впоследствии конкретизированных онлайн-опросом, нами была предпринята попытка выделения параметров проектирования информационной образовательной среды в подготовке кадров высшей квалификации, а именно той ее части, характеризуемой в качестве информационной системы.

Образовательными целями программ подготовки кадров высшей квалификации являются написание научно-квалификационной работы (диссертации), получение квалификации «Исследователь. Преподаватель-исследователь» и овладение определенным набором компетенций с учетом направления подготовки и научной специальности (ФГОС ВО). Исследователи выделяют три группы внешних условий, влияющих на построение траектории достижения вышеозначенных целей. Во-первых, влияние так называемого постиндустриального общества (общества знаний) - на фоне технического прогресса и скорости изменений различных сфер жизнедеятельности информация и такая ее форма, как знание, становятся основным продуктом труда (Э. Тоффлер). Следовательно, успешный специалист должен обладать компетенцией работы с информацией, способностью генерирования знания (А. Ю. Белогуров). Вторым фактором выделяют влияние научного прогресса, а именно усиление профессионального деления в области научного поиска, обусловливающее диверсификацию процесса институализации науки и развитие научного поиска в форме специально организуемых научных исследований, реализуемых в научно-исследовательских, зачастую междисциплинарных группах [4]. В свою очередь этот факт требует учета при проектировании содержания образовательных программ подготовки кадров высшей квалификации (участие обучающихся в коллективных научных исследованиях, развитие междисциплинарной научной коммуникации, методика и практика подготовки грантовой документации, учет возрастающего влияния наукометрики и т. д.). В-третьих, изменение профессиональных требований к педагогу высшей школы также влияет на условия подготовки кадров высшей квалификации. С. А. Писарева, ссылаясь на слова Гессена, отмечает, что особенность преподавания в высшей школе состоит в исследовании, проводимом на глазах обучающегося. Этот тезис в применении к условиям рыночной экономики и высокой конкуренции означает, что приумножение (актуализация) знания возможно при условии совмещения преподавательской функции с исследовательской [5, с. 133]. В-четвертых, способы «налаживания связей» профессии преподавателя высшей школы с окружающей общественностью значительно отличаются от профессий обслуживающего типа, где результат профессионализма виден сразу (врачи, юристы и т. д.). Качество труда преподавателя в силу отложенного проявления результата не может быть оценено непрофессионалами, что является условием автономии, средством контроля и саморегулирования внутри профессии, пример - присуждение ученой степени сообществом профессионалов или государственная итоговая аттестация выпускников вуза [6].

Итак, выделим требования к системе подготовки кадров высшей квалификации, образовательные программы которой должны [4]:

- ориентировать выпускника на сферу будущей исследовательской деятельности, в том числе и подготовить к необходимости выявления области исследования для получения необходимого знания;

- отражать будущую специализацию выпускника не только в наименованиях дидактических единиц учебного плана, но и в организационных формах деятельности, в условиях ее выполнения;

- предоставлять обучающемуся возможность быть субъектом исследовательской деятельности, в том числе и коллективной междисциплинарной; 
- способствовать обучению и развитию академической мобильности.

Таким образом, развитие у выпускника «готовности к исследовательской деятельности» [4] или «исследовательской компетентности» [7] считается главной целью обучения по программе подготовки кадров высшей квалификации. Подчеркивается, что в парадигме компетентностного подхода исследовательская компетентность относится к блоку профессиональных компетенций (С. А. Писарева). Исследовательская компетентность раскрывается в совокупности таких видов деятельности, как:

- разработка методологии и организация исследования (включая выявление проблемных зон в своей и смежных областях науки);

- проведение исследования (в том числе и в составе исследовательских междисциплинарных групп);

- анализ результатов исследования и определение путей их распространения (экспертиза, проектирование способов широкого представления результатов научной и/или профессиональной общественности, использования в других исследованиях) [5, с. 126].

Формирование индивидуального учебного плана предполагает наличие «ориентационного поля» выбора модулей (В. В. Лаптев):

- образовательно-профессиональные дисциплины;

- факультативные дисциплины;

- педагогическая (ассистентская и доцентская) практика;

- научное (диссертационное) исследование;

- подготовка диссертационной работы и представление ее в диссертационный совет;

- итоговая аттестация [7, с. 97].

При этом применение ИКТ целесообразно только в формализуемой части образовательной программы (проведение занятий, планирование научно-исследовательской деятельности, сдача промежуточных аттестаций и т. п.), где явно прослеживается педагогическое влияние информационной образовательной среды [8]. Основная же часть подготовки аспиранта состоит в проведении научных исследований, что является «самостоятельным научным творчеством», не поддающимся формализации [9, с. 75]. Такую позицию занимают и исследователи проблем информатизации высшего образования. И. Г. Розина при описании модели образовательной информационно-коммуникационной среды выделяет применение технологий обучения, средств коммуникаций и учебных электронных ресурсов на этапах «учения» и «обучения» (ОИКС учения и ОИКС обучения) [10, с. 21], С. Л. Атанасян, описывая структуру и содержание информационной образовательной среды педагогического вуза, отмечает необходимость применения средств ИКТ в учебной, научно-методической и организационно-управленческой компонентах [2, с. 30], Н. Б. Стрекалова выделяет четыре блока задач в данном контексте: управление учебным процессом, его информационно-методическое обеспечение, реализация автоматизированного обучения и дистанционное взаимодействие участников образовательного процесса [11].

Анализ реального образовательного процесса позволяет конкретизировать теоретические данные. Так, реализация программ подготовки научно-педагогических кадров в аспирантуре ПСТГУ, имеющих государственную аккредитацию, предполагает централизованное администрирование образовательного процесса силами отдела аспирантуры с участием руководителей образовательных программ и заведующих кафедрами. Всего реализуется восемь программ на девяти кафедрах, расположенных в трех удаленных друг от друга корпусах университета. Организация обучения предполагает такие виды и формы деятельности, как изучение дисциплин, прохождение практик, научные исследования (научное руководство, посеместровое планирование научных исследований и отчет по результатам на 
кафедре), работа аспирантов в малых группах, научно-исследовательские семинары кафедры и научного руководителя, формирование портфолио достижений аспиранта, промежуточные и итоговая аттестации. В связи с этим профессорско-преподавательскому составу, обеспечивающему организацию и реализацию образовательных программ, а также аспирантам было предложено ответить на вопросы о целесообразности, возможных формах и направлениях централизованного применения средств ИКТ в образовательном процессе.

Характерно, что представители ППС рассматривают в качестве мер по усовершенствованию организации образовательного процесса повышение качества и направлений коммуникации и информирования.

Удобная ИОС (информационная образовательная среда) должна быть... устроена по принщипу внутренней социальной сети, позволяющей создавать формальные и неформальные группь (для общения участников семинаров, слушателей лекиий, семинаров научного руководителя, аспирантских и студенческих кружков и т. д.), ведение собственных индивидуальных страничек-блогов (оно может совмещаться с портфолио) (заведующий кафедрой).

$<$ Нужна возможность> посмотреть текущую успеваемость аспиранта, расписание занятий и т. п., сделать... отдельные странички: участие в конференциях, научныле публикации, процесс работы над диссертацией, которые необходимо заполнять на протяжении всего обучения (руководитель образовательной программы).

Хорошо бы... придумать календарь или напоминания, которые бы им (аспирантам) приходили автоматически, что и как они должны делать (руководитель образовательной программы).

В силу индивидуализации образовательного маршрута аспиранты представляют в качестве отчета о проделанной научно-исследовательской деятельности рабочие, итоговые тексты, готовые публикации, сертификаты, письменные заявки на гранты, аннотированные библиографические списки и другие документы, перечень которых затруднительно регламентировать, а сроки сдачи не всегда совпадают с учебным ритмом календарного графика. Поэтому возникает необходимость фиксации и возможности обсуждения (в отличие от простой функции передачи, доступной в электронной почте) документов в электронном виде и перевода отчетности из бумажной формы в электронную.

$<$ Нужен> ресурс, <предоставляюший> возможность хранения, передачи, извлечения файлов с информацией, быстрого реагирования на сообщения (руководитель образовательной программы).

Удобная ИОС должна... быть уменьшающей бумажный документооборот и упрощающей отчетность (заведующий кафедрой).

Также представители ППС сходятся во мнении с аспирантами, что средства ИКТ должны быть направлены на оперативное информирование об учебном процессе и предоставление возможности развития собственного образовательного или исследовательского маршрута.

Я приветствую все формы применения информационных технологий. <Они должны быть ориентированы> на формирование у аспирантов целенаправленного поиска и выявления необходимого материала и корректного его использования (научный руководитель).

Нужна система или база конференций и журналов, <библиотек, грантов, поисковых систем,> где аспиранты могли бы брать нужную им информащию (руководитель образовательной программы).

Аспиранты также предлагают использовать ИКТ для работы в малых группах, для дистанционных лекций, вебинаров, семинаров, удаленного контакта с администрацией. 
Можно создать небольшую электронную библиотеку иностранной литературы, которая будет собрана с помощью аспирантов. Во время обучения аспиранты будут собирать литературу по своей теме. После защиты они могут передать PDF-файльь в данную библиотеку (аспирант третьего года обучения).

$<$ Нужна возможность> общения на нашу тематику между аспирантами по одному направлению (что-то вроде семинара). Мы пока начали с английского разговорного клуба (аспирант первого года обучения).

Также важно отметить опасения ученых, связанные с сохранением пространства свободного научного творчества.

$<$ \рименение ИКТ неприемлемо> при всяком требовании, не имеющем прямого отношения к обеспечению научной работы (научный руководитель).

Итак, с организационно-педагогической точки зрения информационная образовательная среда в подготовке кадров высшей квалификации должна содержать качества информационной системы, направленные на обработку, хранение, получение, обмен информацией в целях обеспечения и сопровождения образовательного процесса. В данном контексте ее главная функция состоит в создании условий развития индивидуальной образовательной траектории обучающегося, как то:

1) стратегическое и оперативное информирование об образовательном процессе;

2) возможность администрирования образовательного процесса на уровне отдела аспирантуры (деканата), кафедр, руководителей образовательных программ;

3) обеспечение широкого выбора способов и форм коммуникации;

4) возможность планирования научно-исследовательской работы, научного руководства, систематизации и накопления в ходе обучения публикаций, сведений и материалов о преподавательской деятельности и иных достижений (портфолио);

5) доступ к специализированным информационным источникам и базам данных;

6) упрощение и автоматизация необходимых процедур отчетности и контроля, нацеленные на высвобождение трудозатрат для научно-исследовательской деятельности.

Подводя итог, отметим, что выявленные в ходе предпринятого исследования критерии могут быть использованы для определения области централизованного применения информационно-коммуникационных технологий при проектировании информационной образовательной среды в подготовке кадров высшей квалификации.

Статья подготовлена в рамках проекта «Информачионная образовательная среда в подготовке кадров высшей квалификачии» при поддержке Фонда развития ПСТГУ.

\section{Список литературы}

1. Малышев В. С. Анализ содержания понятия «информационная образовательная среда вуза» // Сибирский педагогический журнал. 2019. № 1. C. 70-81. DOI: 10.15293/1813-4718.1901.09.

2. Атанасян С. Л. Формирование информационной образовательной среды педагогического вуза: автореф. дис. ... д-ра пед. наук. М., 2009. 49 c.

3. Захарова И. Г. Формирование информационной образовательной среды высшего учебного заведения: автореф. дис. ... д-ра пед. наук. Тюмень: 2003. 46 с.

4. Белогуров А. Ю. Разработка научно-методического обеспечения совершенствования подготовки кадров высшей научной квалификации в условиях послевузовского образования: учеб.-метод. рекомендации. Петропавловск-Камчатский: Изд-во Камчатского гос. ун-та им. Витуса Беринга, 2016. 48 с.

5. Писарева С. А. Проблемы содержания подготовки научно-педагогических кадров в аспирантуре современных университетов // Известия РГПУ им. А.И. Герцена. 2013. № 158. С. 124-135. 
6. Парсонс Т., Сторер Н. Научная дисциплина и дифференциация науки // Курьер Российской академической науки и высшей школы. URL: http://www.courier-edu.ru/pril/posobie/parst.htm (дата обращения: 07.12.2019).

7. Лаптев В. В., Тряпицына А. П., Богословский В. И., Бендюкова Т. С., Писарева С. А. Подготовка кадров высшей квалификации: аспирантура в современном университете / под общ. ред. В. В. Лаптева. СПб.: Книжный дом, 2005. 320 с.

8. Tassos A. Mikropoulos, Antonis Natsis Educational virtual environments: A ten-year review of empirical research (1999-2009) // Computers \& Education. 2011. № 56. P. 769-780.

9. Пучкова А. П., Дворяшина В. П. Направления совершенствования деятельности аспирантуры с применением информационных технологий на примере аспирантуры МЭСИ // Открытое образование. 2008. № 5. С. 74-84.

10. Розина И. Н. Теория и практика обучения педагогической коммуникации в образовательной информационно-коммуникационной среде: автореф. дис. ... д-ра пед. наук. М., 2005. 50 с.

11. Стрекалова Н. Б. Управление качеством самостоятельной работы студентов в открытой информационно-образовательной среде: автореф. дис. ... д-ра пед. наук. Самара, 2017. 52 с.

Малышев Владимир Сергеевич, аспирант, Православный Свято-Тихоновский гуманитарный университет (ул. Новокузнецкая, 23б, Москва, Россия, 115184). E-mail: malyshev.v@pstgu.ru

Материал поступил в редакиию 12.12.2019.

DOI 10.23951/2307-6127-2020-1-146-153

\section{DEFINITION OF THE AREA OF CENTRALIZED APPLICATION OF INFORMATION AND COMMUNICATION TECHNOLOGIES IN THE PROCESS OF TRAINING OF HIGHLY QUALIFIED PERSONNEL}

\section{V.S. Malyshev}

\section{Orthodox St. Tikhon Humanitarian University, Moscow, Russian Federation}

The conditions for reforming the system of training of highly qualified personnel are characterized by the growing need to process large amounts of information in professional activities. Against this background, the graduate of the training program of the highest qualification should be ready to independently identify problem areas for the purpose of individual or collective research and obtain new knowledge aimed at solving the tasks. It follows that the content of the training program should include the forms and types of future professional activity of the graduate. The undertaken research is aimed at identifying the means of information and communication technologies that can be centrally applied to ensure the educational process, in order to create the basic conditions that will allow to identify the right direction of the individual educational trajectory of the student during the development of the training program of the highest qualification. This article describes the identification of a specific sphere of centralized application of information and communication technologies in the design of information educational environment in the training of highly qualified personnel on the basis of theoretical and empirical analysis of educational process of training of teaching staff in graduate school.

Keywords: information educational environment in the training of highly qualified personnel, design parameters, educational process in graduate school.

\section{References}

1. Malyshev V. S. Analiz soderzhaniya ponyatiya "informatsionnaya obrazovatel'naya sreda vuza" [Analysis of the content of the concept "information educational environment of the university"]. Sibirskiy pedagogicheskiy zhurnal - Siberian Pedagogical Journal, 2019, no. 1, pp. 70-81. DOI: 10.15293/1813-4718.1901.09 (in Russian).

2. Atanasyan S. L. Formirovaniye informatsionnoy obrazovatel'noy sredy pedagogicheskogo vuza. Avtoref. dis. dokt. ped. nauk [Formation of information educational environment of pedagogical university. Abstract of thesis doct. of ped. sci.]. Moscow, 2009. 49 p. (in Russian). 
3. Zakharova I. G. Formirovaniye informatsionnoy obrazovatel'noy sredy vysshego uchebnogo zavedeniya. Avtoref. dis. dokt. ped. nauk [Formation of information educational environment of higher educational institution. Abstract of thesis doct. of ped. sci.]. Tyumen', 2003. 46 p. (in Russian).

4. Belogurov A. Yu. Razrabotka nauchno-metodicheskogo obespecheniya sovershenstvovaniya podgotovki kadrov vysshey nauchnoy kvalifikatsii v usloviyakh poslevuzovskogo obrazovaniya: uchebno-metodicheskiye rekomendatsii [Development of scientific and methodological support of advanced training personnel of higher scientific qualification in the conditions of postgraduate education: educational and methodical recommendations]. Petropavlovsk-Kamchatskiy, Kamchatka State University Publ., 2016. 48 p. (in Russian).

5. Pisareva S. A. Problemy soderzhaniya podgotovki nauchno-pedagogicheskikh kadrov $v$ aspiranture sovremennykh universitetov [Problems of the content of training of scientific and pedagogical personnel in graduate school of modern universities]. Izvestiya RGPU im. A. I. Gertsena - Izvestia: Herzen University Journal of Humanities and Sciences, 2013, no. 158, pp. 124-135 (in Russian).

6. Parsons T., Storer N. Nauchnaya distsiplina i differentsiatsiya nauki [Scientific discipline and differentiation of science]. Kur'yer Rossiyskoy akademicheskoy nauki i vysshey shkoly - Courier of Russian academic science and higher education (in Russian). URL: http://www.courier-edu.ru/pril/posobie/parst.htm (accessed 7 December 2019).

7. Laptev V. V., Tryapitsyna A. P., Bogoslovskiy V. I., Bendyukova T. S., Pisareva S. A. Podgotovka kadrov vysshey kvalifikatsii: aspirantura v sovremennom universitete [Training of highly qualified personnel: postgraduate studies at a modern University]. Saint Petersburg, Knizhnyy dom Publ., 2005. 320 p. (in Russian).

8. Tassos A. Mikropoulos, Antonis Natsis Educational virtual environments: A ten-year review of empirical research (1999-2009). Computers \& Education, 2011, no. 56, pp. 769-780.

9. Puchkova A. P., Dvoryashina V. P. Napravleniya sovershenstvovaniya deyatel'nosti aspirantury s primeneniyem informatsionnykh tekhnologiy na primere aspirantury MESI [Directions of improvement of activity of postgraduate study with application of information technologies on an example of postgraduate study of the Moscow economic and statistical Institute]. Otkrytoye obrazovaniye, 2008, no. 5, pp. 74-84 (in Russian).

10. Rozina I. N. Teoriya i praktika obucheniya pedagogicheskoy kommunikatsii v obrazovatel'noy informatsionno-kommunikatsionnoy srede. Avtoref. dis. dokt. ped. nauk [Theory and practice of teaching pedagogical communication in educational information and communication environment. Abstract of thesis doct. of ped. sci.]. Moscow, 2005. 50 p. (in Russian).

11. Strekalova N. B. Upravleniye kachestvom samostoyatel'noy raboty studentov v otkrytoy informatsionno-obrazovatel'noy srede. Avtoref. dis. dokt. ped. nauk [Management of independent work of students in the open information and educational environment. Abstract of thesis doct. of ped. sci.]. Samara, 2017. 52 p. (in Russian).

Malyshev V. S., Orthodox St. Tikhon Humanitarian University (ul. Novokuznetskaya, 23b, Moscow, Russian Federation, 115184).E-mail: malyshev.v@pstgu.ru 